\title{
Droit et violence dans la littérature du Moyen Âge, études réunies par Philippe Haugeard et Muriel Ott
}

\section{Maria Colombo Timelli}

\section{(2) OpenEdition}

1 Journals

\section{Édition électronique}

URL : http://journals.openedition.org/studifrancesi/304

DOI : $10.4000 /$ studifrancesi.304

ISSN : 2421-5856

Éditeur

Rosenberg \& Sellier

\section{Édition imprimée}

Date de publication : 1 avril 2015

Pagination : 118-119

ISSN : 0039-2944

\section{Référence électronique}

Maria Colombo Timelli, «Droit et violence dans la littérature du Moyen Âge, études réunies par Philippe Haugeard et Muriel Ott », Studi Francesi [En ligne], 175 (LIX | I) | 2015, mis en ligne le 01 avril 2015, consulté le 18 septembre 2020. URL : http://journals.openedition.org/studifrancesi/304 ; DOI : https:// doi.org/10.4000/studifrancesi.304

Ce document a été généré automatiquement le 18 septembre 2020.

\section{(c)}

Studi Francesi è distribuita con Licenza Creative Commons Attribuzione - Non commerciale - Non opere derivate 4.0 Internazionale. 


\title{
Droit et violence dans la littérature du Moyen Âge, études réunies par Philippe Haugeard et Muriel Ott
}

\author{
Maria Colombo Timelli
}

\section{RÉFÉRENCE}

Droit et violence dans la littérature du Moyen Âge, études réunies par Philippe HAUGEARD et Muriel отт, Paris, Classiques Garnier, 2013, pp. 279.

1 Ce recueil, résultat d'un colloque qui s'est déroulé en mars 2012 à Mulhouse, est organisé en quatre sections.

2 La première partie porte l'intitulé «Penser le droit, le pouvoir et la force». En mettant en relation le procès contre Ganelon qui clôt la Chanson de Roland avec la présentation du même personnage au début du texte, puis avec l'opposition entre Roland et Olivier, Florence GOYET montre bien la complexité idéologique que cache une présentation apparemment simple. Le procès final met en scène en effet des conflits de personnages et de visions politiques que le poème avait déjà développés et qui ont également droit de cité dans la chanson de geste (Le procès dans la "Chanson de Roland", homologue de la démarche épique, pp. 21-38). Une relecture de l'attitude du gardien de taureaux que rencontre Calogrenant au début du Chevalier au lion à la lumière des interprétations grégoriennes de la Genèse permet selon Éléonore ANDRIEU de mieux comprendre le sens et la fonction de la violence exercée par ce personnage sur ses bestes, ainsi que leur apparente liberté dans l'essart ("Si le destraing par mi le cors": droit et violence dans l'essart, pp. 39-51). Sur la base d'un corpus antique et médiéval (Marie de France, Eude de Cheriton, Nicole Bozon), Christopher LUCKEN relève que les fables où s'affrontent la brebis et le loup s'inscrivent dans un contexte judiciaire; c'est au lecteur que revient la tâche d'exprimer un jugement capable de rétablir le droit et la justice au-delà même de 
la force des prétendants et de la fausseté des témoins ("La raison du plus fort". Le témoignage de la fable, pp. 53-71).

Cinq articles composent la deuxième partie, «Pratique judiciaire et motif littéraire». Claude Roussel propose la lecture comparée de scènes de duel judiciaire dans un groupe nourri de chansons de geste du XIV siècle. Reflet d'usages juridiques réels, celui-ci sert le but apologétique de textes où un monde désordonné et parfois chaotique trouve, au moins provisoirement, le rétablissement des valeurs de la justice (Le duel judiciaire dans les chansons de geste tardives, pp. 75-89). Jérôme DEVARD compare la pratique judiciaire du bannissement au traitement que lui réservent le Roman de Renart d'une part et les chansons de geste contemporaines de l'autre (Huon de Bordeaux, Renaut de Montauban). Dans les fictions épiques, ce qui compte, plutôt que l'exactitude judiciaire, c'est la réflexion sur la justice royale et ses conséquences sociales, dans un monde où Dieu est l'unique garant de la vérité ("Qui bon i vont, mal en revenent". La pratique du bannissement épique aux XII ${ }^{e}-\mathrm{XII}{ }^{e}$ siècles. Triomphe de la violence et échec du droit, pp. 91-104). Sophie ALBERT examine les personnages impliqués dans les scènes d'humiliation - roi, cité, héros-chevalier - dans trois récits: Aiol, Tristan de Béroul, Meliadus; elle montre comment les textes littéraires visent à promouvoir la classe chevaleresque: le protagoniste n'est jamais véritablement coupable, et le roi exerce non pas la justice mais une violence illégitime, alors que la voix du peuple - que le souverain peut écouter ou non - est souvent représentée sous un jour négatif (Droit et violence dans l'humiliation publique du chevalier, pp. 105-119). Patrick MORAN analyse le rôle joué par Symeu, personnage certes secondaire dans le Lancelot-Graal, mais qui se trouve au centre d'un certain nombre d'épisodes significatifs (dans l'Estoire, la Queste, le Lancelot) dans lesquels émerge une fois de plus la succession entre Lancelot et Galaad (Châtiment divin et délivrance dans le "Cycle Vulgate", pp. 121-134). Nicolas LOMBART relit Le Prisonnier desconforté du château de Loches, long poème anonyme composé vers 1488 , très représentatif de la poésie carcérale $\mathrm{du} \mathrm{xv}^{\mathrm{e}}$ siècle. Le texte est fortement marqué par la présence du protagoniste, qui exprime, outre son angoisse spirituelle, un profond sentiment de révolte contre l'arbitraire judiciaire et une conscience de la dissidence qui paraît anticiper les expressions des Réformés du siècle suivant (L'emprisonnement, un supplice paradoxal, pp. 135-152).

4 Les articles réunis dans la troisième partie, «Démesure de la violence et limites du droit», proposent encore une réflexion entre textes littéraires et réalité juridique de leur époque. Dorothea KULLMANN offre ainsi une lecture «juridique» de Jaufré: la comparaison entre les épisodes de cruauté, violence, punition, dans le roman et dans les Usatges de Barcelona (collection de coutumes sans doute $\mathrm{du} \mathrm{XI}$ e siècle) révèle, par-delà les analogies et les différences, une clé d'interprétation du roman complémentaire, mais tout à fait intéressante (Droit et violence dans le roman de "Jaufré", pp. 155-168). Lydie Louison souligne l'omniprésence de la violence dans Cristal et Clarie, sous les formes les plus diverses: géants et démons, larrons et brigands, chevaliers et dames, savent tous faire preuve de la plus grande cruauté. Si le héros s'emploie à la punir, c'est d'abord en l'absence du roi Arthur et de tout cadre judiciaire; d'autre part, il peut luimême être mis en accusation, et il s'avère finalement coupable d'avoir pris par la force la chasteté de Clarie (Crimes et châtiments dans le "Bas Pays" de "Cristal et Clarie", pp. 169-184). Sarah BAUDELLE-Michels analyse le remaniement en prose de Renaut de Montauban par David Aubert. Dans cette réécriture, qui fait une large place aux aspects matériels et économiques, les épisodes de vol abondent et le «prosateur» ajoute de son 
cru les jugements que ceux-ci exigent. Ce qui interroge le lecteur moderne, c'est d'abord le dévoiement des Quatre Fils Aymon eux-mêmes, qui s'adonnent à des vols, mais surtout l'absence de toute punition à leur égard. La réalité bourguignonne des années 1460 perce peut-être dans cet ouvrage, mais sans pouvoir réellement entamer le prestige traditionnellement rattaché à la noblesse (Le vol et le droit dans la prose bourguignonne de "Renaut de Montauban", pp. 185-199).

La quatrième partie réunit trois contributions à sujet plus proprement historique («Le témoignage de l'histoire»). Benoît-Michel тоck rappelle les violences qui secouèrent les Flandres entre l'assassinat du comte Charles en mars 1127 et l'avènement de son successeur Thierry en juillet 1128. Les sources narratives latines conservées montrent néanmoins la persistance de la notion de «droit» (canonique et féodo-vassalique, pratique du serment juridique) même en des moments aussi troubles ("Crimina universo mundo execrabilia", pp. 203-218). Bernard RIBÉMONT examine un autre cas d'espèce: la ville de Cambrai et sa région, dont l'histoire semble profondément marquée par la violence, mais aussi par l'adoption, dès 1227, de la «loi Godefroy», loi constitutionnelle qui restera une référence jusqu'au $\mathrm{xVI}^{\mathrm{e}}$ siècle (Réglementation de la violence en contexte urbain (XII $-\mathrm{XVI}^{e}$ siècle), pp. 219-238). L'article de Florence TANNIOU concerne enfin les Mémoires de Philippe de Novare, œuvre apologétique du lignage de Beyrouth contre Frédéric II: Philippe oppose la violence illégitime de l'Empereur au droit coutumier de Chypre et de Jérusalem, qui légitime et régule l'emploi même de la force ("Esgart de court", "Espee forbie". Droit et violence dans les "Mémoires" de Philippe de Novare, pp. 239-252).

6 Il faudra encore souligner l'intérêt de la «Bibliographie» (pp. 253-266), qui sépare les sources primaires citées dans les textes, et deux sections thématiques: «Histoire et droit», «Droit et littérature». Suivent encore l'«Index des auteurs ou des titres d'œuvres» (pp. 267-269) et l'«Index des thèmes» (pp. 271-275). 